VOL 4 (2020) NO 4

e-ISSN : 2549-9904

ISSN : 2549-9610

\title{
Assessing Financial Sustainability of Community Network Project through e3value Modelling and Simulation
}

\author{
Cheah WaiShiang ${ }^{\# 1}$, Chong XingZi ${ }^{\# 2}$, Muhammad Asyraf bin Khairuddin ${ }^{\# 3}$, Nurfauza binti Jali ${ }^{\# 4}$, \\ Rahmat Hidayat*

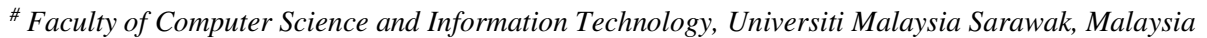 \\ E-mail: ${ }^{1}$ wscheah@unimas.my,' ${ }^{2}$ kmasyraf@unimas.my \\ * Department of Information Technology, Politeknik Negeri Padang, Sumatera Barat, Indonesia \\ E-mail:rahmat@pnp.ac.id
}

\begin{abstract}
Many efforts had been done to make ICTs available in rural area to increase their incomes and productivities. For example, a community ecommerce is introduced to promote community handicraft and income generation; other projects like deploying VSAT to improve the internet connectivity at rural area. Although the project is developed, it is facing a challenge like how to sustain the ICT4D projects? This paper presents the study of financial sustainability of community network project through e3value modelling and simulation. Financial sustainability is one of the important factor for community projects. As a NGO or researcher that is trying to help the community, is it possible for us to access the feasibility of any projects for communities so that a realistic suggestion or proposal can be planned? To sustain the community commerce, it cannot be denied that a well planning and measurement on financial sustainability of the projects is required. Hence, we believe that e3value can be used as a tool to measure the financial sustainability of community network projects. With the use of 3value model, it can serve as a reference for various parties in resolving the financial sustainability issue.
\end{abstract}

Keywords - ICT4D; e3value; community network project; financial sustainability.

\section{INTRODUCTION}

ICT4D refers to the application of information and communication technologies toward social, economic, and political development, with a particular emphasis on helping poor and communities. To date, lots of ICT4D projects have been introduced to bridge the digital gaps between rural and urban area of Sarawak. Although lots of ICT4D projects are deployed, it is still suffering from sustainability. Sustainability refers to support, maintenance, to keep something in perpetuation, to avoid failure, to keep alive or regenerate. Furthermore, it known as development that meets the needs of the present without compromising the ability of future generations to meet their own needs.

From the review, there are five dimension of sustainability, which are economic, social, institutional, technological and environmental [1]. Financial sustainability refers to the financial aspect of projects; social sustainability refers to the acceptance and adoption of technology among community; technological sustainability refers to the robustness, reliability of hardware and software due to rapid changes of the technology; environmental sustainability refers to ecological impact during the development and deployment of projects. To access the sustainability of projects, framework, methods have been introduced.

Several works have been introduced to propose framework, methods to assess or study the sustainability of ICT4D projects. However, the existing works are still suffering from a systematic and comprehensive manner to evaluate various sustainability dimension of ICT4D projects. Hence, this led to the failure of most ICT4D projects [2]. Work has been done to study the financial sustainability of ICT4D projects through e3value [3]. Continue from the success of the financial sustainability study, this paper introduces the study of community network projects through e3value modelling and simulation.

As described in [2] there have many issues widely encountered to impede the deployment of ICT4D project. High rates of failure are reported for ICT4D project although the project gets many investments from stakeholder. The failure of ICT4D project is caused by un-needed ICT project or un-suitable technology to rural community. To reduce the failures rate of ICT4D projects, financial sustainability assessment of rural connectivity project needs to be 
conducted before implementing the ICT4D project as reported in this paper.

\section{Literature Review}

The notion of sustainability study is conducted by several researchers. [4] focuses on a strategy to evaluate socioeconomic aspect of ICT4D projects. The paper presents a design framework to evaluate the outcome of communitybased tele-centres. The paper describes the challenges that were encountered in developing a suitable design framework to conduct the study. In presenting the research design, the author discusses the rationale, and motivations for various design decisions. Additionally, the paper highlights the short sightedness of implementers of ICT4D projects in incorporating monitoring and evaluation strategies during the conceptualization and implementation of ICT interventions.

[5] presents the financial and social sustainability study of eCenter project in Kyrgyzstan. Using a mixed-method approach, they found that coupon scheme can support the financial and social aspect of eCenter. With fee-based ICT services, the telecentre can generate income. Meanwhile, the coupon scheme able to encourage community and new comer to use the services at eCenter.

e3Value models is adopted to study the economic sustainability of ICT services for rural poor in sub-Sahara Africa [6]. With e3value model, a mobile voice-based web service project is accessed. It has been reported that the mobile web services are feasible and sustainable in a longer run and are these results applicable to other rural areas in Sub Saharan Africa.

e3Value business model is introduced by Gordijn, J. and Akkermans, $\mathrm{H}$ in year 2001. The e3value model focuses on identifying and analyzing on value creation, exchange and consumption within a multi actors network [7]. Then, e3value model helps policy maker in making decision [8]. With e3value model, it able to models an economically independent entity, example; enterprises and end consumers or profit and loss responsible business units.

The e3value model consists some technical terms, example actor, value transaction, value network, value object and others [9]. The actor refers to consumer, stakeholders, customers, partners, government and end-users. Each transaction between the actors refer to value object. The value transactions are playing role as economic value exchanges in the business model [10]. Then, value network able to show relation and transaction among the actors in this business model. The model has capability to analyze how the network creates and delivers value [10]. Furthermore, the model facilitates the users in checking numerical computation involve in the projects [11]. When all the data or value enters e3value model, user can simulate the model. The data will produce in spreadsheet. This model is helpful for the researchers to analyze the financial sustainability of the projects [12].

\section{THE MATERIAL AND METHOD}

Telecommunication towers are built to enable mobile digital communication among people. Tower are built by contractors. All the wireless communication devices such as radio broadcasting, mobile networking, television antennas and so on are connected using the telecommunication tower.
In mid-term review Eleventh Malaysia Plan 2016-2020, the digital infrastructure such as 1,000 telecommunication towers will be upgraded and 300 new towers will be constructed to increase coverage and quality of broadband services in rural areas in the remaining plan period [13].

In Sarawak, Sacofa Sdn Bhd is one of the company that provide telecommunication infrastructure in Sarawak. Sacofa sustains their business by providing services like tower space rental, network equipment, fiber core rental, bandwidth service and local access network. Sacofa provides tower space to all operator (E.g., DiGi, Maxis, Celcom and etc) to setup the mobile network infrastructure. In this case, the operators pay the license fees to rent the tower space for mobile communication businesses. The construction of tower project is required to deal with a contractor. Sacofa has to be received fund by government in this project due to the highest cost in constructing a tower. Meanwhile, community need to pay mobile subscription for mobile phone call and internet access.

It has been reported that mobile communication is the needs of community nowadays. The Covid19 pandemic has created a new norm in which students are having online classes and tutorials most of the time; marketing or selling products and services are handled online; meetings are conducted online and etc. Hence, the internet accessibility is one of the challenges for Sarawak rural community. Although company can install tower to increase the network coverage, how sustainable of community networking projects?

The e3value model for community network project is designed to describe the relationship between stakeholders or multi-actor comprehensively. With e3value model, the community network project is evaluated by calculating the net value flow sheet and presents the relationship between needs and value objects.

Several steps are required when conducting financial sustainability of ICT4D projects through e3value [14]. There are,

Step 1: Concisely state the financial sustainability of community connectivity project idea.

Step 2: Represent the financial sustainability of community connectivity project idea as an e3value diagram.

Step 3: Attribute the constructs in the e3value diagram with numbers.

Step 4: Assess economic sustainability from a structural point of view.

Step 5: Assess economic sustainability from a quantitative point of view.

Step 6: Refine the financial sustainability of community connectivity project idea with e3value model.

Step 7: Observation and discussion.

\section{RESULTS AND DISCUSSION}

The details of each steps in accessing the financial sustainability of community connectivity project is elaborated as following.

Step 1: Concisely state the financial sustainability of community connectivity project idea.

The idea of community connectivity projects is elaborated in this step. An elaboration on how mobile network service operates for the community, actors involved in the project 
and the relationship between the actors through e3value modelling are presented in this step.

As mentioned before, tower provider (Sacofa) sustains their business for community by providing bandwidth services, tower service and Internet service to mobile operators. The tower contractor is to construct tower whereas the tower provider is to provide tower space to all operators (E.g., DiGi, Maxis, Celcom) who are interested to the tower project. Besides, operators have to pay a license fees of the tower project to tower provider for tower space rental and they will get the tower space to provide mobile and Internet service for the community. Finally, communities can enjoy the mobile and Internet service from operator.

The actors that are involved in this project are tower contractor, tower provider, operator and communities. Table I shows the actor and role of each actors in this project.

TABLE I

ACTORS AND ROLE DESCRIPTIONS

\begin{tabular}{|l|l|}
\hline \multicolumn{1}{|c|}{ Actor } & \multicolumn{1}{c|}{ Role Descriptions } \\
\hline Tower contractor & Construct tower. \\
\hline Tower provider (Sacofa) & $\begin{array}{l}\text { Provide tower space to all } \\
\text { operator (E.g., DiGi, Maxis, } \\
\text { Celcom). }\end{array}$ \\
\hline Operator & $\begin{array}{l}\text { Pay a license fees of the tower } \\
\text { project to tower provider and } \\
\text { get the tower space to provide } \\
\text { mobile and Internet service for } \\
\text { the community. }\end{array}$ \\
\hline Communities & $\begin{array}{l}\text { Get mobile and Internet service } \\
\text { from operator. }\end{array}$ \\
\hline
\end{tabular}

Table II shows the example of monetary and nonmonetary value actor. The actor who have contributed or involved in any financial activity is known as monetary value actor whereas the actor who did not contribute or involve in any financial activities is known as non-monetary value actor. As the connectivity project are costing, hereby all the actors are involved in monetary transaction

TABLE III

EXAMPLE OF MONETARY AND NON-MONETARY VALUE ACTOR

\begin{tabular}{|l|c|}
\hline \multicolumn{1}{|c|}{ Monetary Value Actor } & Non-monetary Value Actor \\
\hline Tower contractor & - \\
\hline Tower provider & - \\
\hline Operator & - \\
\hline Communities & - \\
\hline
\end{tabular}

Step 2: Represent the financial sustainability of community connectivity project idea in an e3value diagram.

Fig. 1 shows the e3value model community connectivity project. The e3value is constructed by using the e 3 value software tool called e3value editor and it can generate a net value flow sheet. As shown in Table 1, there are four actors involved in the project. They are tower contractor, tower provider (e.g., Sacofa), operators (e.g., DiGi, Maxis, Celcom) and communities. The market segment notation that shows in communities represents many actors of the same kind and share the same economic value in the model. Actor requires value objects act as a product or a service that has an economic value for at least one of the actors to conduct exchange value object process in the model. For example, money, tower, tower space or Internet.

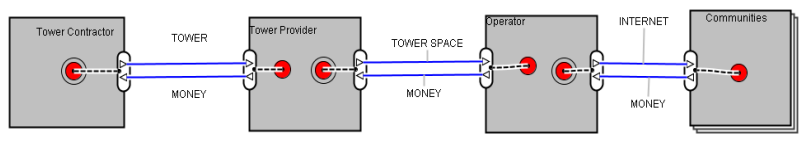

Fig. 1 Example of e3value model for mobile network service

Step 3: Attribute the constructs in the e3value diagram with numbers.

The steps involve quantifying the e3value model to assess economic sustainability of ICT4D project. The quantification is done based on the following rules. By generating net value flow sheet, an e3value model have to attribute with numbers. Many model elements can be quantified in e3value model. Example of model elements include the number of customer needs per time frame and the number of actors in a market segment and the valuation of an object exchanged [15]. If all the required model elements have an appropriate quantification, we can generate a new value flow sheet for each actor. To design a business model using e3value, quantification acts as an estimation or assumption. The quantification should be based on the actual number of case if the assessment is done while the ICT4D service is already operating [14].

Table III shows the tower construction cost estimation. For quantification of product and service, we assume that the tower construction cost will not exceed RM1,400,000.00 based on the Table III. All the tower construction cost estimation is mentioned by the expert personnel who works as a network engineer in Sacofa.

TABLE III

EXAMPle OF MONETARY AND NON-MONETARy VALUE ACTOR

\begin{tabular}{|l|c|}
\hline \multicolumn{1}{|c|}{ Tower Type } & $\begin{array}{c}\text { Construction Cost } \\
\text { Estimation(RM) }\end{array}$ \\
\hline Monopole (without cabin) & $250,000.00$ \\
\hline Monopole (with cabin) & $450,000.00$ \\
\hline Monopole Tree (without cabin) & $400,000.00$ \\
\hline Monopole Tree (with cabin) & $650,000.00$ \\
\hline 3 Legged Tower ( 200ft ) & $350,000.00$ \\
\hline 3 Legged Tower ( 250ft ) & $450,000.00$ \\
\hline 3 Legged Tower ( 300ft ) & $650,000.00$ \\
\hline 3 Legged Tower ( 350ft ) & $800,000.00$ \\
\hline 4 Legged Tower ( 200ft ) & $400,000.00$ \\
\hline 4 Legged Tower ( 250ft ) & $600,000.00$ \\
\hline 4 Legged Tower ( 300ft ) & $1,200,000.00$ \\
\hline 4 Legged Tower ( 350ft ) & $1,400,000.00$ \\
\hline
\end{tabular}

Table IV shows the prices of products and services for the mobile network service. Tower provider (Sacofa) pays RM1,400,000.00 to the tower contractor. Based on the Table 4 , we assume that operator have to pay the highest license fee of the $400 \mathrm{ft}$ height of single operator tower with RM23,874.38 per month to Sacofa for tower space rental. Meanwhile, the communities pay RM80.00 per month to the operator for Internet service.

TABLE IV

Prices Of Products And Services For The Mobile Network Service

\begin{tabular}{|l|l|}
\hline \multicolumn{1}{|c|}{ Value Object } & \multicolumn{1}{c|}{ Value (Ringgit Malaysia) } \\
\hline Tower & RM1,400,000.00 \\
\hline Tower space & RM23,874.38 per month \\
\hline Internet service & RM80.00 per month \\
\hline
\end{tabular}


For quantification of the number of actors, we assume that there are 700 communities in the rural area which represents by using a market segment symbol as shown in the e3value model in Fig. 1

Step 4: Assess economic sustainability from a structural point of view.

There has some information on economic sustainability can be done by observations without doing calculations. The observations can be done by collecting data from useful resources such as Internet and based on the e3value model of mobile network service that we constructed for modelling. This is because the e3value can performed a clear graphical structure and provide a net value flow sheet that are useful for sustainability assessment.

Step 5: Assess economic sustainability from a quantitative point of view.

In this step, e3value software is used to conduct a quantitative analysis of e3value model. The net value flow sheet for each actor can be generated using e3value editor software. We assume that the time frame that will be used in this research is one year. If all actors in the project have positive net value flow, it means the ICT4D project to be sustainable. If the net value flow is negative, it means that the ICT4D project cannot produce a sustainable result. The analysis result of mobile network service presents in this step.

Fig. 2 shows the net value flow sheet for the Tower Contractor. It can be known as the profitability sheet or net cash flow sheet. The net value flow sheet is presented in the spreadsheet Excel file format. In the spreadsheet, there consists of net value flow for tower contractor, tower provider, operator and communities. Assumed that the tower construction cost for 1 year is RM1,400,000.00. Tower provider (Sacofa) have to pay the tower construction cost of the 350ft height of 4 Legged Tower with RM1,400,000.00 to the tower contractor based on the Table III. So, tower provider (Sacofa) is allocating RM1,400,000.00 to pay for the tower contractor to construct tower. The net value flow sheet shows in Fig. 2 shows the net value flow for each actor involved and the net value flow sheet for tower contractor is making a profit of RM1,400,000.00. It shows the positive net value flow for Tower Contractor.

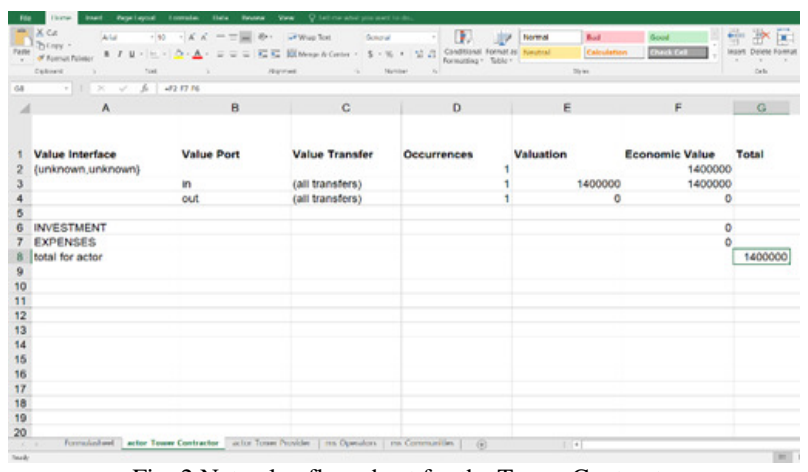

Fig. 2 Net value flow sheet for the Tower Contractor

Fig. 3 shows the net value flow sheet for the Tower Provider (Sacofa). Based on the Fig. 3, the highest monthly license fee for single operator tower built (Zone D) in Sacofa is selected for this calculation. The monthly license fee is
RM23,874.38. The monthly license fee amount for the 1 year of contract period is equivalent to 12 months of contractual fees, as shown in Fig. 3. In this case, operator need to contribute RM286,492.56 to the tower provider (Sacofa). Tower provider (Sacofa) pay RM1,400,000.00 to the tower contractor for tower construction. The tower provider (Sacofa) will be the non-profit actors as the total for actor shows negative in Fig. 3.

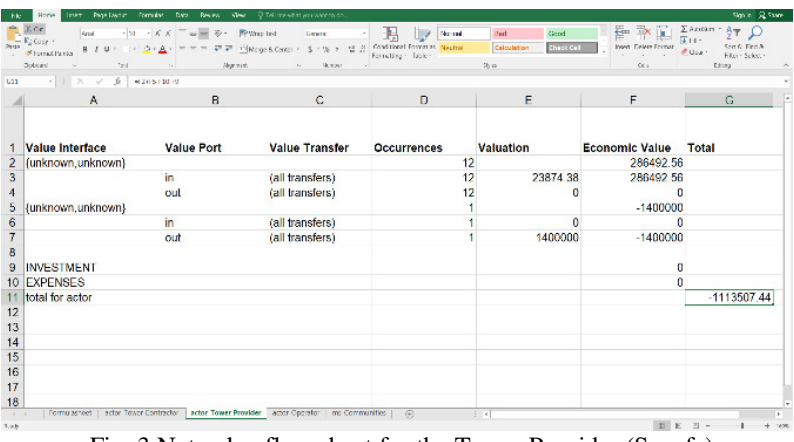

Fig. 3 Net value flow sheet for the Tower Provider (Sacofa)

Fig. 4 shows the net value flow sheet for the Operator. The operator should pay the license fee of RM23,874.38 per month and received the tower space service for them to provide their mobile and Internet services to the community. Communities should pay the telco fee for Internet service. The value for Internet service is RM80.00 per month. Assumed that the number of communities are 700. The number of customer needs in this model is 8400 per year. So, the occurrences will be 8400 as represents the number of customer needs.

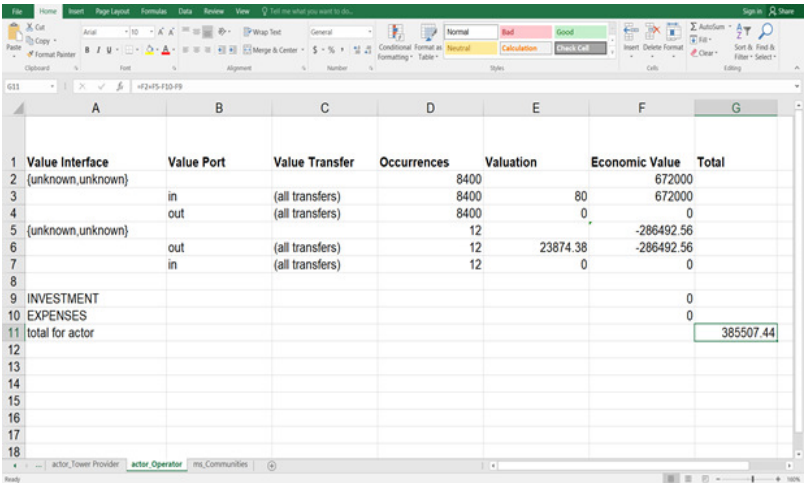

Fig. 4 Net value flow sheet for the Operator

Fig. 5 shows the net value flow sheet for the Communities. Communities should pay the Internet service with RM80.00 per month. As mentioned before, we assume 700 as the number of communities. The occurrences will be 8400 as represents the number of customer needs per year. Based on the Fig. 5, the communities' actor will be the non-profit actors as the total for actor shows negative and produce a negative cash flow due to their expenditures in Internet service.

The proposed sustainability analysis is presented in this section. From the analysis, it shows that the model did not produce a sustainable result. In order to improve the model, the e3value model need to be changed or modified. We can indicate which actors or parts having financial issue through the net value flow that generated by e3value editor software. 


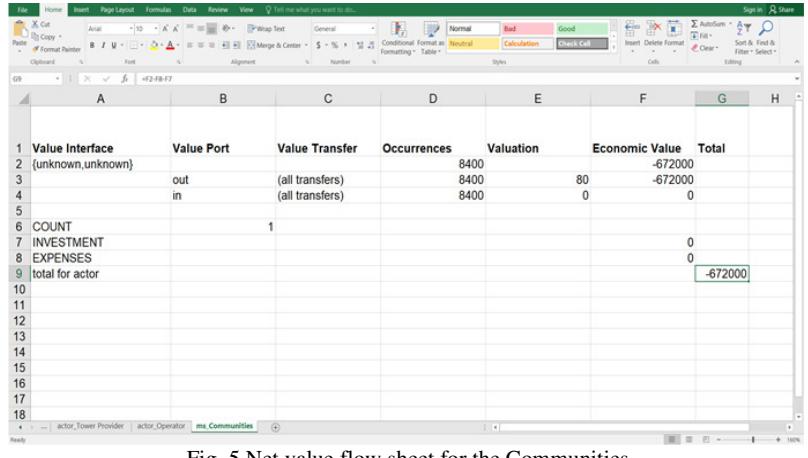

Fig. 5 Net value flow sheet for the Communities

Step 6: Refine the financial sustainability of rural connectivity project idea with e3value model

From the analysis, it shows that the model did not produce sustainable result because there have negative net value flow for certain actors. The actors that cannot be sustained in the model are tower provider (Sacofa) and communities because they have negative net value flows. This caused the model cannot be sustainable. The model can only be sustainable if all the actors in the network have positive net value flows. If the network has negative net value flows, the model cannot be sustainable. The model need to be changed or modified by changing the quantification of this model. We can modify the actor values through assumptions so that the model can produce a positive net value flow for all actors.

Profit is the crucial factor that leads to the financial sustainability of tower project. The profit from stakeholders, tower space service and so on will take as operating costs in the analysis whereas the operational cost which including utility bills, maintenance cost and so on will affect the sustainability of rural connectivity project. Higher cost of hardware and low return on investment (ROI) lead to the exclusion of the community to setup a tower in their area. Meanwhile, some rural community with low income level are unable to afford the costly Internet access.

From the financial accessibility of tower project, to achieve long-term financial sustainability, funding is essential to develop for initiating ICT4D project. Besides that, people need to spend more time to understand the rural community by working with them in order to create a sustainable rural connectivity projects. Meanwhile, a clear understanding should be created concerning on financial sustainability of rural connectivity project before the development of ICT4D project [16].

Table V shows the net cash flow for the actors in mobile network project. Based on the results, the model did not produce a sustainable result for certain actors. The tower contractor and operator shows sustainable with a positive cash flow whereas the tower provider and communities is not sustainable with a negative cash flow. Tower provider cannot be sustained in this model because it caused by the high expenses on purchasing for tower construction in a short term which is 1 year. In fact, the income that received from the operator is not enough to cover its expenses. So, the prices to be paid by the operator should be increased on the long term. We recommended that the term of tower rental service between tower provider and operator need to be increase and increase the tower space rental license fees. This can help to improve the tower provider's profit. Also, the tower provider should actively promote the tower rental to other telcoms. For communities' actor in e3value model, it shows that it is not sustainable with a negative cash flow.

TABLE V

Net Cash Flow For The Actors In Mobile Network Project

\begin{tabular}{|l|l|}
\hline \multicolumn{1}{|c|}{ Actor } & \multicolumn{1}{c|}{ Total for actor (RM) } \\
\hline Tower contractor & $1,400,000.00$ \\
\hline Tower provider (Sacofa) & $-1,113,507.44$ \\
\hline Operator & $385,507.44$ \\
\hline Communities & $-672,000.00$ \\
\hline
\end{tabular}

\section{CONCLUSIONS}

This paper presents the adoption of e3value model for calculating the financial sustainability of ICT4D project using the e3value graphical editor and generate net value flow sheet in the e3value editor software. The result from the e3value model can be used to determine which actor is making profit and which one is not. From this information, we know that e3value helps on understanding e-business innovation. However, it cannot help on understanding the behaviour and performance of system in real world. Therefore, a simulation process is needed to study how the human behaviour effect on the business performance. The modelling and simulation process for mobile network service through dynamic model is required to be conducted to overcome the limitation of e3value on simulating human behaviour.

\section{ACKNOWLEDGMENT}

The funding for this project is made possible through the research grant obtained from UNIMAS under the grant [F08/SpFRGS/1529/2017].

\section{REFERENCES}

[1] Hanss, D., \& Böhm, G. (2012). Sustainability seen from the perspective of consumers. International Journal of Consumer Studies, 36(6), 678-687.

[2] WaiShiang, C., Jali, N., Khairuddin, M. A., \& Sharbini, H. (2017). Understanding Technology Changes for ICT4D Projects through Modelling. Journal of Telecommunication, Electronic and Computer Engineering (JTEC), 9(3-3), 147-151.

[3] Bon, A., Gordijn, J., Akkermans, H., de Boer, V., Baart, A., Shiang, C. W., \& San Nah, S. (2019, May). Community-centered, Projectbased ICT4D Education in the Field. In International Conference on Social Implications of Computers in Developing Countries (pp. 386397). Springer, Cham.

[4] Pather, S., \& Uys, C. (2010, January). A strategy for evaluating socio-economic outcomes of an ICT4D programme. In 2010 43rd Hawaii International Conference on System Sciences (pp. 1-11). IEEE.

[5] Best, M. L., Thakur, D., \& Kolko, B. E. (2009, April). The contribution of user-based subsidies to the impact and sustainability of telecenters-the eCenter project in Kyrgyzstan. In 2009 International Conference on Information and Communication Technologies and Development (ICTD) (pp. 192-200). IEEE.

[6] Bon, A., Gordijn, J., \& Akkermans, H. (2020). E-Service Innovation in Rural Africa Through Value Co-Creation. In Disruptive Technology: Concepts, Methodologies, Tools, and Applications (pp. 859-877). IGI Global.

[7] Daaboul, J., Castagna, P., Da Cunha, C., \& Bernard, A. (2014). Value network modelling and simulation for strategic analysis: a discrete event simulation approach. International Journal of Production Research, 52(17), 5002-5020.

[8] Laurier, W., \& Poels, G. (2013). Invariant conditions in value system simulation models. Decision Support Systems, 56, 275-287. 
[9] Gordijn, J., \& Akkermans, H. (2001). Designing and evaluating ebusiness models. IEEE intelligent Systems, (4), 11-17.

[10] Daoudi, J. (2017). Economic Sustainability of ICT Services for the Rural Poor in sub-Sahara Africa.

[11] Caetano, A., Antunes, G., Pombinho, J., Bakhshandeh, M., Granjo, J., Borbinha, J., \& Da Silva, M. M. (2017). Representation and analysis of enterprise models with semantic techniques: an application to ArchiMate, e3value and business model canvas. Knowledge and Information Systems, 50(1), 315-346.

[12] Laurier, W., \& Poels, G. (2009). Conceiving e3-value Business Plans. In Workshop on Value Modeling and Business Ontologies.
[13] Ministry of Economic Affairs. (2018). Mid-term Review of the Eleventh Malaysia Plan 2016-2020

[14] WaiShiang, J. G. C., Bon, A., \& Akkermans, H. Understanding financial sustainability of ICT services for social and economic development using e3value. (2020)

[15] Gordijn, J., Yu, E., \& Van Der Raadt, B. (2006). E-service design using $i^{*}$ and e/sup 3/value modeling. IEEE software, 23(3), 26-33.

[16] Shiang, C. W., Halin, A. A., Lu, M., \& CheeWhye, G. (2016). Long Lamai Community ICT4D E - Commerce System Modelling: An Agent Oriented Role - Based Approach. The Electronic Journal of Information Systems in Developing Countries, 75(1), 1-22. 